\title{
Usina de Extração de Gordura de Dendê para Produção de Biodiesel é Inaugurada no Pará
}

por Guilherme B. C. Martins

Data de publicação na Web: 15 de fevereiro de 2013 Recebido em 7 de novembro de 2012 Aceito para publicação 10 de fevereiro de 2013

Empresa Vale inaugurou no Pará recentemente (26/06/2012) uma usina extratora de gordura de dendê, a Biopalma. O objetivo da empresa é produzir biodiesel a partir do óleo de dendê visando uma produção de 600 mil toneladas de biodiesel a partir de 2015, quantidade suficiente para sustentar sua frota automobilística e maquinaria, mobilizando para isso um investimento de 500 milhões de reais.

A iniciativa da empresa é inovadora e objetiva com a verticalização da produção de combustível, e o uso de uma matriz energética mais limpa. Segundo a empresa, a planta é capaz de processar 120 ton/h do fruto de dendê, obtendo 25 ton/h de gordura de palma. Já é previsto pela empresa a criação de uma segunda unidade com capacidade de processamento de 680 ton $/ \mathrm{h}$ do fruto, de modo a ser a segunda maior do mundo nesse segmento. 0 investimento tem também um impacto direto no mercado de energia, pois é previsto que a planta produza $11 \mathrm{MW}$ de eletricidade limpa, dos quais 3,5 MW serão utilizados internamente e o restante será disponibilizado para concessionárias do estado. A planta prevê, ainda, a utilização dos resíduos gerados como adubo, de modo a criar um processo sustentável.

Apesar do uso do dendê para biodiesel não ser novidade, a iniciativa da Vale em utilizar essa oleaginosa para a produção de biodiesel em larga escala é inovadora no Brasil. A principal matériaprima utilizada para produção de biodiesel no país atualmente é o óleo de soja, de modo que a participação do dendê nesse setor é insignificante, como pode ser observado na Figura 1.

O azeite ou gordura de dendê, também conhecido como palma, é a gordura mais produzida e consumida no mundo. $O$ dendê se adapta a solos levemente ácidos, necessitando de uma quantidade regular de chuvas e luminosidade, com temperaturas na faixa de 23 a 27 o $C$, encaixando-se perfeitamente no clima da região norte do Brasil, onde se pode obter até 8 ton/ha/ano de gordura. Outra vantagem do dendê é o seu rendimento de material graxo, superior em até 10 vezes ao do óleo de soja. O dendê começa a frutificar a partir de 3 anos depois de plantado, fornecendo frutos por um período de 25 anos, com uma produção que se estende durante todo o ano. Esta é mais uma das vantagens do dendê, pois elimina custos com armazenagem como é necessária para a soja e outras oleaginosas durante os períodos de entressafra.

A gordura de dendê é utilizada nos seguintes segmentos: i) indústria alimentícia, diretamente na fabricação de pães ou para processos de frituras; ii) área medicinal, devido à presença de antioxidantes e em dietas específicas; iii) cosméticos e saneantes, como por exem- 
plo detergentes, xampus e emulsificantes; e iv) indústria química como fonte de obtenção de insumos químicos, tais como ácidos graxos, ésteres, glicerina, entre outros. No entanto, seu uso principal é na indústria alimentícia, correspondendo a $80 \quad \%$ desse mercado.

O mercado de biodiesel no Brasil está em crescente expansão. Em 2011 o consumo de biodiesel foi de 2,431 bilhões de litros excedendo em mais de 100 \% a produção de 2008, quando foi iniciada a obrigatoriedade do uso do biodiesel. A produção de biodiesel de dendê prevista pela vale corresponde a aproximadamente $20 \%$ do biodiesel consumido atualmente, sendo uma quantidade significativa para o mercado. A Vale também prevê a utilização da blenda B20 (20\% biodiesel; $80 \%$ diesel) em sua frota, uma mudança significativa se comparada ao exigido pela legislação atual que é de $5 \%$.

A recente inauguração da usina e seus futuros projetos são uma iniciativa inovadora e importante para a indústria energética brasileira. Tanto o estímulo de uma "nova" matéria-prima no setor, assim como a utilização de uma blenda B20, gera uma nova tendência no mercado de biodiesel. 0 projeto também caracteriza uma importante expansão da indústria oleoquímica no Brasil, em razão da sua variedade e aplicação, assim como na região norte especificamente, expandindo o cultivo de dendê. Esse fato ilustra a importância da oleoquímica no Brasil para o desenvolvimento econômico, tecnológico e sustentável do país.

\section{Agradecimentos}

O autor agradece às diferentes agências que financiam as pesquisas do Grupo de Pesquisas Rede de Estudos em Oleoquímica (CNPq, FINEP, FAPEAL, FAPDF), ao INCT-CATÁLISE e em especial à CAPES (PROCAD 2005, Projeto no 0023051; e PROCAD NF 2009, Projeto no 735/2010) que permitiram a mobilidade de alunos e professores das equipes. $\mathrm{O}$ autor agradece também ao CNPq e CAPES pelas bolsas de pesquisa concedidas aos pesquisadores e alunos de graduação e pós-graduação.

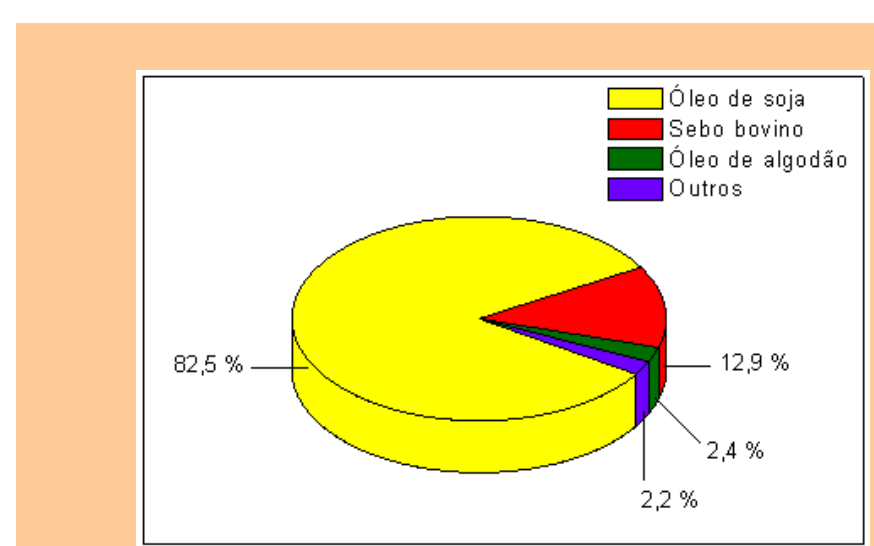

Figura 1. Matérias-primas utilizadas na produção de biodiesel no Brasil em 2011

Universidade de Brasília, Laboratório de Materiais e Combustíveis, Instituto de Química, CP 4478, CEP: 70904-970, Brasília-DF, Brasil.

Mbandeira007@gmail.com

DOI: 10.5935/1984-6835.20130012 